\title{
Preserving Health Rights of Female Sex Workers (FSWs): Are we doing Justice?
}

Kiran Mubeen* and Marina Baig

Aga Khan University School of Nursing and Midwifery, Karachi, Pakistan

*Corresponding author: Mubeen K, 395/3, Inara Palace, Flat \# 102, Pedro Desouza Road, Garden East, Karachi, Pakistan, Tel: 92 333 3181331; E-mail: kiran.mubeen@aku.edu

Received date: April 21, 2015; Accepted date: August 07, 2015; Published date: August 12, 2015

Copyright: $\odot 2015$ Mubeen K. This is an open-access article distributed under the terms of the Creative Commons Attribution License, which permits unrestricted use, distribution, and reproduction in any medium, provided the original author and source are credited.

\begin{abstract}
:
In Pakistani context where majority of the population are Muslims, prostitution is considered as stigma. Health providers often come across a challenge to provide optimal care to prostitutes when their own values and beliefs contradict with their professional obligations. This commentary article is based on a clinical case study in which a family planning counselor failed to respond to the contraceptive needs of a prostitute due to the non-supportive state policy for tubal ligation and provider's own values for the stigmatized profession. This paper introduces a question for all health providers whether this act was justifiable on the basis of human rights paradigm, right for autonomy and principal of non-maleficence. This article is a commentary against the incomplete state policy of family planning and ethical principles violated in this case.
\end{abstract}

Keywords: Health rights; Stigma; Non-maleficence

\section{Introduction}

It is a common practice for public health providers to address the health needs of larger population; however at times, while doing this, they often overlook the health rights of those individuals who are among the minorities in the society. On ethical grounds, such health policies must be questioned that pose discrimination against the rights of a certain minority population. Healthcare professionals often come across such circumstances, yet having correct knowledge of ethical principles, theories and adequate reasoning skills may lead to correct decision making. In this commentary article we have selected a case study of a prostitute, who is a member of a minority group, hence is often neglected in Pakistani society.

\section{Case Study}

This is a true case study of a 20 year old unmarried woman, who visited a family planning (FP) center and explored from the counselor regarding permanent method of family planning for herself. At first, this was surprising for the counselor, but after rapport building and probing, the woman verbalized that she has multiple sexual partners who pay money to her for rendering services. In order to prevent pregnancy for the rest of her life, she intends to have tubal ligation. In response, the family planning counselor explained her, the policy of tubal ligation that includes several clauses out of which the women was not meeting the following two criteria. Firstly, she should have at least two children, and secondly, it requires the written informed consent of both husband and wife in every case prior to the procedure [1]. After listening to the counselor, the women tried to explain her circumstances and begged for support, but counselor refused to offer any help. Since the woman was not meeting the criteria, she had to leave the family planning center with regret.

\section{Prostitution in Pakistani Context}

Prostitution is a business or practice of providing sexual services to another person in exchange of money [2]. In many parts of the world, women choose this profession voluntarily to overcome their poor financial circumstances, whereas some are coerced to enter this profession through trafficking, violence or kidnapping. However, in Pakistan prostitution is considered as a dishonored, stigmatized, and illegal profession not only because of cultural and religious restrictions, but also due to its associated hazards to the clients. A qualitative study conducted in three randomly selected cities of Punjab (biggest province of Pakistan) explored reasons for choosing this profession from 33 FSWs. Poverty, early marriages, domestic violence, family issues including husband's drug abuse and illness of a family member were reported as major factors for adopting this profession [3]. A 2005 study estimated the relative size of FSW population as almost seven FSWs per 1000 men ranging from 13,000 encounters per month in Hyderabad to more than 650,000 per month in Lahore. The major client hubs after Lahore are located in Karachi $(2,19,000)$, Sukkar $(1,07,000)$ and Multan with similar client volume as Sukkar [4]. Since this occupation is illegitimate in the country so it is difficult to estimate the true numbers of clients volume at present, however the reported statistics suggest a huge population utilizing these services.

A 2011 mapping study estimated 73,675 FSWs in 12 major cities of Pakistan. Out of 4301 respondents in all four provinces, majority (59.8\%) was married and only $48.7 \%$ were literate. Their median age was 26 years out of whom $9.7 \%$ were under 20 years. Majority of the FSWs were home based (45.2\%) and remaining were street based and kothikhana based (small brothels), whereas brothel based were only $7.5 \%$. These findings indicate that due to illegitimacy of the profession, the FSW are least concentrated in brothels and majority of them work in hidden places which are difficult to reach and their individual and structural vulnerabilities may differ. Although the prevalence of HIV is lowest amongst FSWs (0.63\%), studies reported that other STIs and unsafe abortions are very common amongst them and they possess inadequate knowledge regarding STIs and its prevention [5]. For example, a cross sectional study surveyed 730 FSWs in three areas of Lahore mapped during 2004 study. Although the sample was not 
representative of entire country, the study determined that $75 \%$ of the respondents considered STIs as having leucorrhea or AIDs whereas remaining $25 \%$ could not even name a single STI. Moreover, $65 \%$ acquired STI during past six months out of whom only $28 \%$ sought treatment. Ninety percent of them reported having an abortion at least once in their life time (Range 1-6) out of which 33\% reported seeking abortion services from unskilled birth attendants [6].

\section{Our Position and Rational}

The analysis of the above case study highlights two important issues, which are discussed as under:

First of all, the present state policy regarding permanent family planning method is very general, therefore, does not have any provision for the woman in this case study. Although in general, FSWs come in the category of women, however they have some different health needs. There basic health needs involve contraception to prevent unsafe abortions and protection against STIs including HIV/ AIDs. In this policy the contraceptive needs of prostitutes are not properly addressed. Till this time, most of the work has been done on HIV and STI prevention, which is beneficial for the general clients and community at large, however, health of the sex workers, by restricting unsafe abortions have not been taken into account. Therefore, we argue that such policies need serious revision that is infringing the health rights of prostitutes.

Second of all, in this case study, the provider displayed a biased attitude against the prostitute. Though the counselor in her position complied with the state law, but, ethically she should have provided health education for safe sexual practices and could have offered temporary methods of contraception. The attitude of the counselor showed disregard and discrimination, which translated into her action by showing apathy for woman's circumstances. The provider breeched the ethical principles of non-maleficence and right to autonomy. Due to this reason, we assert that providers should perform risk benefit analysis while working with prostitutes.

\section{Discussion}

\section{Rights based theory}

"Rights are justified claims that individuals can make on other individuals or on society. Having rights means to be in a position to determine, by having choices what others should or should not do" [7]. In this case study, the basic need of woman that is family planning was not fulfilled due the state policy that is very superficial and does not address the need of prostitute. This woman demanded for sterilization because she was at risk of multiple unwanted pregnancies. In Pakistani context, abortions are condemned, resulting in most of the women seek abortion services outside medical facilities. This woman must have recognized the complications associated with unsafe abortions, and decided for opting sterilization; whereas, due to the failure of state policy regarding sterilization deprived her from her rights for claiming health care. The UN Global strategy for women's and children's health accounted preventable maternal mortality and morbidity as human rights violation $[8,9]$. Hence, if this woman dies due to complication of unsafe abortion then state may be held accountable for her preventable death. Considering the vulnerability and hazards associated with prostitution, the state should create some feasibility in the reproductive health policies based on their occupational needs.

\section{Right to autonomy}

Furthermore, in this case study, the principle of respect for autonomy was also compromised. Autonomy involves respecting the autonomous agents by acknowledging their rights to hold views, to make choices and take decisions according to their values and believes [7]. According to the principle of autonomy this woman being an autonomous individual has the right to take decision for her own body based on her occupational hazards. However, the state policy did not allow her to opt for this decision either. Similarly, the health provider also failed to safeguard the right of autonomy of this woman, by not providing complete information to her. Principle of autonomy also includes developing capacities for autonomous choices to help them reach correct decision for themselves [7]. The provider should have briefed the lady with all the possible risks and benefits of her decision of sterilization and other methods, and then should have asked the woman to take decision on her own.

\section{The principle of non-maleficence}

Obligations of non-maleficence include not to inflict harms and also not to impose risks of harm [7]. The principal of non-maleficence supports several specific moral rules. In this case study, the specific rule of 'do not cause pain or suffering' was compromised. State policy is responsible for imposing risk of harm and suffering to this woman. Every time she will be involved in sexual activity her risk of pregnancy and unsafe abortion will definitely be increased.

Moreover, the stereotype behavior of the health provider was also harmful. Yet the woman was not eligible for tubal ligation, but being a health care provider it was the counselor's prime responsibility to share information for safe sexual practices and offer her temporary methods of contraception that she usually offers to other clients during her practice. The apprehensive behavior of the counselor was perhaps based on her own values and believes regarding the stigmatized profession; on the basis of which she discriminated the woman from others. As a result, the woman may not seek medical care in future. Kurtz et al. (2005) reported from focus group finding of 25 FSWs in USA that street based female sex workers managed stigmatizing attitudes of providers by not disclosing their prostitution status to them or did not seek medical care because of an expectation of disrespect and discrimination. Ultimately, many prostitutes seek healthcare when their condition has reached its advanced stages. This act of omission has not only put the woman's life at risk, but also her customers and their families.

\section{Conclusion}

Prostitution, although an illegal, on the other hand, is a popular and demanding profession in Pakistani society like in the other parts of the world. This is a minority and a disadvantaged group surrounded by problems of poverty, helplessness and unwanted diseases. Being health professionals, it is our ethical responsibility not to stigmatize them, rather encourage them to seek help whenever they enter medical facilities. In addition, there should be no discrimination among human rights because every individual has equal right to pursue health.

In the present case study, we learnt that the current state policy for family planning is very fragile and does not have place for marginalized group; therefore the health rights of the prostitutes are not protected. At present, there is no space for prostitutes in existing law because prostitution is condemned in Islam. However, state 
Citation: Mubeen, Baig (2015) Preserving Health Rights of Female Sex Workers (FSWs): Are we doing Justice?. J Clinic Res Bioeth 6: 232. doi:

Page 3 of 3

should introduce rules and policies that support the rights of prostitutes in order to protect health of community at large.

\section{Recommendations}

The role of health professionals should be dominant in promoting health rights of prostitutes by educating sex workers regarding the health problems associated with their profession. Media should be dominant in providing true picture of this profession to eliminate stigma and discrimination of marginalized women, and raising empathy for them amongst general public. Policy makers need to revise family planning policy for the inclusion of this neglected group. Government should allow access to health free of charge near brothels and in areas where prostitution is concentrated. Reproductive health professionals should be trained to work with prostitute women, as any act of omission may cause life threatening consequences. The goal of the training programs should be to develop partnership with prostitutes to support them for prevention of mortality due to unsafe abortions and STIs.

In our literature search we could not find any paper on aspect of prostitution from religious point of view. This area is important to effectively lay the argument for preserving rights of prostitutes in Islamic country and will serve as the basis for translating health rights of prostitutes into a state policy.

\section{Acknowledgements}

We would like to acknowledge the Bioethics faculty Dr. Rozina Karmaliani and Dr. Robina Khan for their guidance and support.

\section{Conflict of Interest}

The authors do not have any conflict of interest.

\section{References}

1. USAID (2009) Manual of National Standards for Family Planning Services. FALAH project for Ministry of Population Welfare, Pakistan.

2. World Health Organization (1998) STD Control in Prostitution Guidelines for Policy. WHO Consultation on Prevention and Control of Sexually Transmitted Diseases in Population Groups at Risk. Geneva.

3. Qayyum S, Iqbal MM, Akhtar A, Hayat A, Janjua IM, et al. (2013) Causes And Decision of Women's Involvement into Prostitution And Its Consequences In Punjab, Pakistan. Academic Research International 4: 398-411.

4. Blanchard JF, Khan A, Bokhari A (2008) Variations in the population size, distribution and client volume among female sex workers in seven cities of Pakistan. Sex Transm Infect 84: 24-27.

5. Mishra S, Thompson LH, Sonia A, Khalid N, Emmanuel F, et al. (2013) Sexual behaviour, structural vulnerabilities and HIV prevalence among female sex workers in Pakistan. Sex Transm Infect 89: ii34-42.

6. Khan MS, Unemo M, Zaman S, Lundborg CS (2011) Health-seeking behavior of women selling sex in Lahore, Pakistan. International Journal of STD \& AIDS 22: 376-380.

7. Beauchamp TL, Childress JF (2009) Principles of Biomedical Ethics. Oxford University Press, USA, pp. 1-4.

8. Cook RJ (2013) Human rights and maternal health: exploring the effectiveness of the Alyne decision. The Journal of Law, Medicine \& Ethics 41: 103-123.

9. Ross MW, Crisp BR, Månsson SA, Hawkes S (2012) Occupational health and safety among commercial sex workers. Scand J Work Environ Health 38: 105-119. 